\title{
Economical Set-up for Foot and Ankle Practice for Underdeveloped Countries
}

\author{
Rajiv Shah
}

\begin{abstract}
Elements of ideal but economical foot and ankle set up for developing countries are a consulting and waiting room with dedicated space for dressings and radiography. Set up needs to have facilities for weightbearing radiographs and foot lab. Foot lab shall have gadgets like monofilament, biothesiometer, vascular Doppler, Harris met and foot scan if possible. The team shall consist of dressing, foot lab and radiography technicians, medical social worker and counsellor. The medical care team shall have on panel services of diabetologist, general and vascular surgeons, plastic surgeon, physiotherapist, orthotist and internal physician. This team shall run various clinics, like adult, pediatric, sports and diabetic foot and ankle clinics. Clinic must take up events for social obligation and must brand itself through the knowledge spreading events as well as through the efforts of prevention.
\end{abstract}

Keywords: Foot and ankle, Underdeveloped countries, Center of excellence.

How to cite this article: Shah R. Economical Set-up for Foot and Ankle Practice for Underdeveloped Countries. J Foot Ankle Surg (Asia-Pacific) 2014;1(2):78-80.

Source of support: Nil

Conflict of interest: None

\section{CHALLENGES FACED FOR FOOT AND ANKLE PRACTICE IN UNDERDEVELOPED COUNTRIES}

There are huge numbers of suffering foot and ankle cases in underdeveloped countries. These cases are either mismanaged or neglected. This is due to the fact that foot and ankle orthopedics has yet to establish itself as the specialty of orthopedics in developing countries. The other reason could be lack of knowledge about the availability of foot and ankle solutions in society as well as in medical population! $!^{1}$ Lack of availability of specific implants and high end equipment also adds to these problems.

\section{What are the Root Reasons for These Problems?}

Underdeveloped country population has now evolved from barefoot walking to utilization of fancy footwear. Like western world, footwear does create unique foot and

\section{Director}

Department of Foot and Ankle Orthopedics, Sunshine Global Hospital, Surat, Gujarat, India

Corresponding Author: Rajiv Shah, Department of Foot and Ankle Orthopedics, Sunshine Global Hospital, Surat, Gujarat India, Phone: 02653938300, e-mail: rajivortho@gmail.com ankle issues in underdeveloped countries. There also is a steep rise in sports population in developing countries. These competing sports population of underdeveloped countries has also contributed a rise in sports related foot and ankle problems. Diabetes is now no more a disease of upper class. It has similar or more prevalence in underdeveloped countries like in the developed countries. Typical issues of diabetic foot now require a worthy attention by medical fraternity even in developing countries.

\section{Is There a Way Out?}

Time has come where orthopedic surgeons from developing countries need to look at west to get foot and ankle education. Specialty can only be developed by such enthusiastic trained orthopedic population from underdeveloped countries. ${ }^{1}$ Their responsibility is to set centers of excellence of foot and ankle care in their own, underdeveloped countries. Such centers of excellence would deliver comprehensive care under one roof. These centers have an obligation not only to treat ailments but also to spread awareness about availability of such advanced foot and ankle care solutions among the population. Looking to limited resources availability in underdeveloped countries, setting up of such a set up needs to be economical in nature and should still serve the aims and objectives.

\section{ELEMENTS OF ECONOMICAL FOOT AND ANKLE SET UP}

Foot and ankle set up in underdeveloped countries needs to be self-sufficient but comprehensive. A consulting room of $10 \times 12$ feet may work well. There needs to be $\mathrm{X}$-ray view box, a computer and a low height couch for patient examination. A walking space to examine gait inside the consulting room is a must. Adjoining to the consulting room, there should be a waiting and reception space of about $8 \times 10$ feet where patients and relatives are well attended by receptionist. A footlab and dressing cum X-ray room are essential part of such a set up. The space required for both is approximately 300 square feet. All tables in footlab as well as dressing room should be of low height. A portable X-ray unit $(60 \mathrm{~mA})$ would suffice the need. Special X-ray stand and wooden cassette holder are required for taking weight-bearing $X$-rays (Figs 1 and 2). These could be easily prepared by a carpenter at the cost of about 12000 to 15000 INR. Dressing room can have a 
small partitioned area of $4 \times 3$ feet for X-ray developing. Digitalization of $X$-ray could be done in next phase where console can be kept in consulting room to avoid duplicating cost of air-conditioning.

Footlab should have equipment like biothesiometer (Fig. 3), hand held vascular Doppler (Fig. 4) and Harris met (Fig. 5). These are essential for diagnosis of neuropathy,

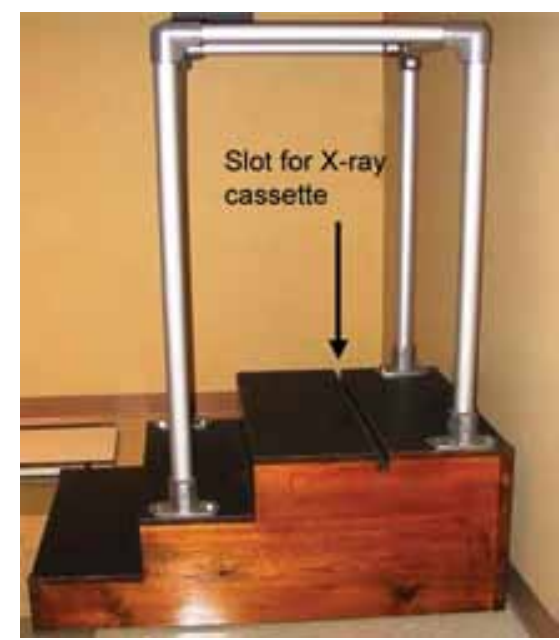

Fig. 1: Stand for weightbearing X-rays with a slot for $\mathrm{X}$-ray cassette

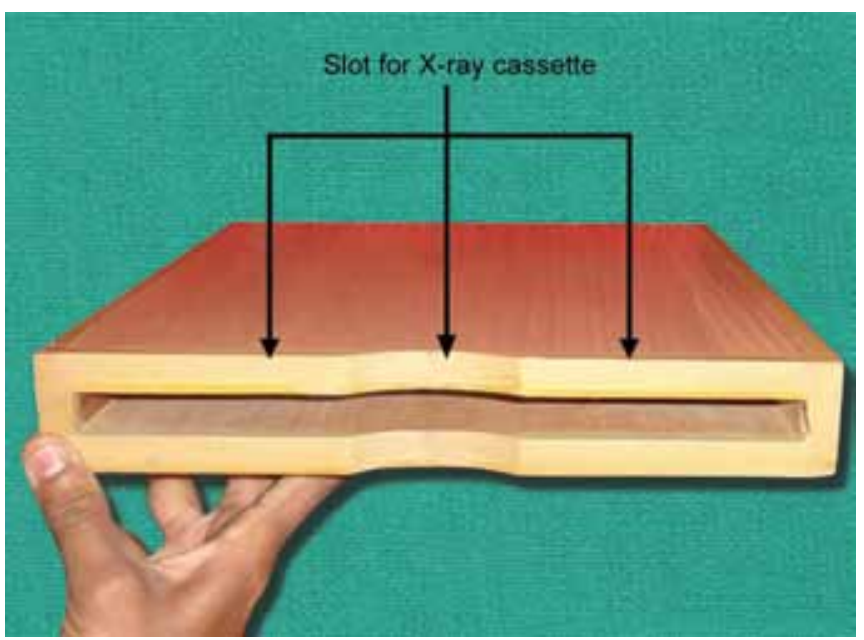

Fig. 2: Wooden box for weightbearing $X$-rays for foot

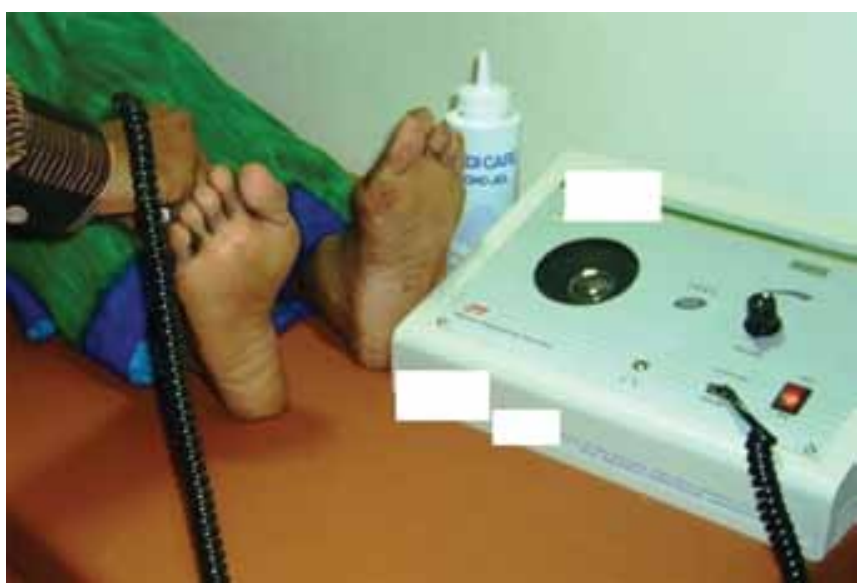

Fig. 4: Vascular Doppler to detect vascularity assessment of vascular status and assessment of plantar pressures respectively.

Together these gadgets will cost less than 75000 INR. These facilities should be erected in such a manner that single technician can run all activities, like footlab, dressing and radiography.

Foot and ankle center needs a space of about 500 to 600 square feet and can be erected with investment of maximum 4,00,000 INR. It can be on any floor provided good elevator facility is available. Center is run by maximum two trained staff. The running cost of center should come to less than 75,000 INR per month. Surgeries could be done at any available bigger set up in vicinity. In operation theater for foot and ankle surgery, a mini saw and burr drive is a must. Foot and ankle instrument drum set may be carried by a surgeon which must consist of some specialized instruments, like lamina spreaders, Hintermann retractor and a set of mini osteotomes, chisel and gouges. Cost of all may be up to 25,000 INR.

\section{ACTIVITIES BY FOOT AND ANKLE SET UP}

Over and above patient care activities, such foot and ankle centers in underdeveloped countries need to work

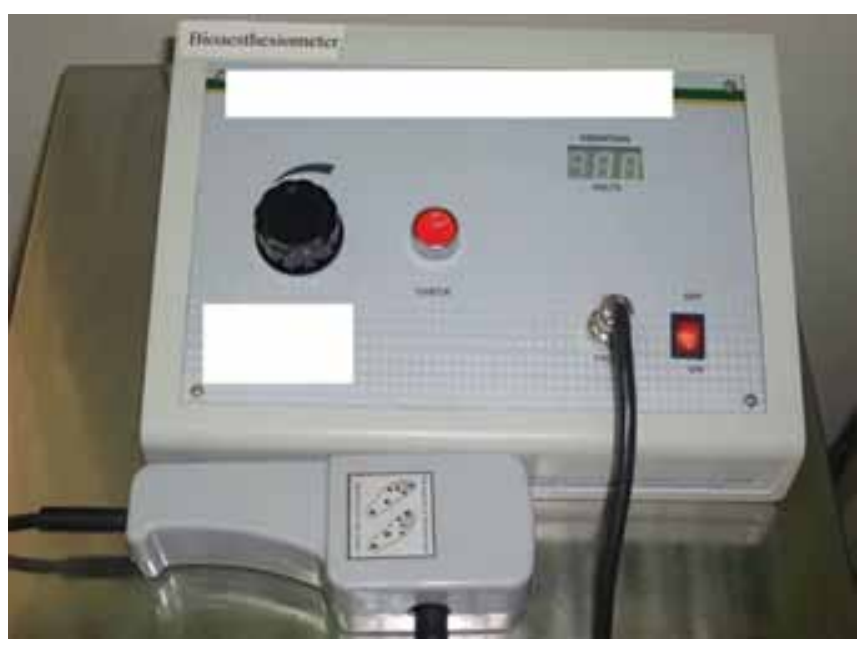

Fig. 3: Biothesiometer to detect neuropathy

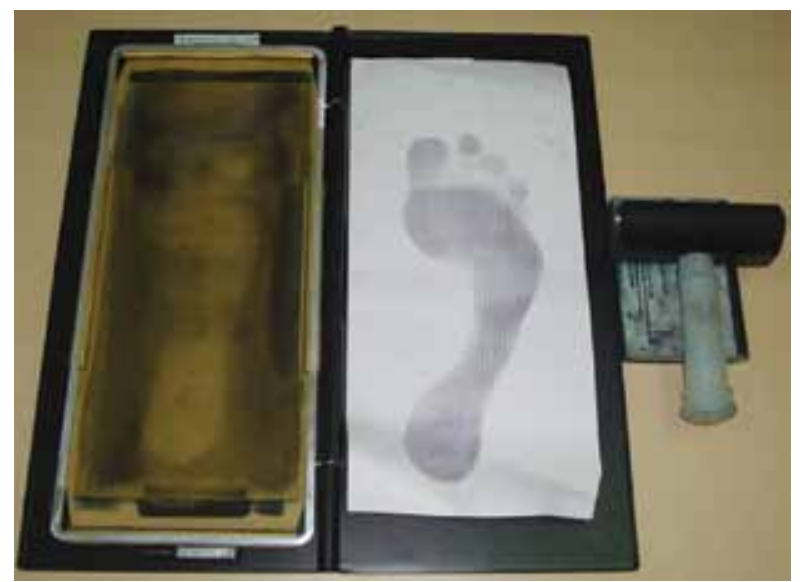

Fig. 5: Harris met to detect plantar pressure 
extensively in the area of prevention. Center should join hands with medical socialworkers and nongovernment organizations (NGO) for such social cause. Programs of social obligation consist of educating masses in the area of special foot care in diabetics. Education is aimed at prevention of amputations in diabetics with the help of specially designed programs.

Center can also educate sports population in the area of proper footwear selection and periodic evaluation of footwear. Such a center shall run specialized diabetic and sports foot and ankle clinics. In India, foot and ankle clinic came up with a novel concept of 'Foot School' which is an educational and interactive workshop of 2 hours where foot and ankle problems, its solutions, myths and realities are discussed by experts through the audiovisual media. ${ }^{1}$

\section{REFERENCE}

1. Rajiv S. Indian foot and ankle scenario. Foot and Ankle specialist. J Asia Pacific Foot Ankle Soc 2011 Sep,4:390-395. 